\title{
From Nigeria with love?
}

\section{Over slachtoffers en daders van online datingfraude}

\author{
Sigrid van Wingerden
}

\section{Introductie}

De zomervakantie: een reis naar een warm land, lekker eten en drinken, zon, zee, en... een vakantieliefde. Waar je twintig jaar geleden je vakantie op Kreta door moest brengen om die charmante, aantrekkelijke Griek te ontmoeten, of naar Rio de Janeiro moest reizen om die mooie, flamboyante Braziliaanse tegen te komen, zijn er tegenwoordig geen reizen naar buitenlandse bestemmingen meer nodig om de man of vrouw van je dromen tegen te komen. Door datingsites op internet kun je op ieder moment van de dag op zoek naar de ware, waar ook ter wereld.

Op zo'n relatiesite ontmoet een Nederlandse vrouw een knappe Amerikaan. Al snel verplaatst het contact zich naar WhatsApp en wordt de vrouw bedolven onder de attente appjes. Toevallig blijkt de Amerikaan ook weduwnaar te zijn en een tienerdochter te hebben. En hij blijkt ook dezelfde hobby's te hebben. Wat een match! $\mathrm{Na}$ een aantal weken intensief heen en weer geappt te hebben, blijkt de man echter wat tegenslagen voor zijn kiezen te krijgen. Dan komt de vraag of de vrouw hem uit de brand zou kunnen helpen door hem wat geld voor te schieten. Hij belooft het zo snel mogelijk terug te betalen, want hij heeft het geld wel op een buitenlandse rekening staan - een print screen van het saldo van zijn bankrekening wordt mee geappt -, maar de rekening is geblokkeerd en om bij het geld te komen moet hij eerst kosten maken. Als de vrouw een paar honderd euro betaald heeft, blijkt de man weer pech te hebben: hij moet een duur visum kopen, hij moet een nieuwe investering doen in apparatuur voor zijn werk, hij moet de medische kosten betalen voor zijn zieke dochter, en zo gaat het maar door. Terwijl de vrouw - hevig verliefd en in het volste vertrouwen dat het geld ieder moment terugbetaald zal worden - haar laatste spaargeld via Western Union overmaakt naar haar nieuwe liefde, blijkt een ontmoeting tussen de twee nooit plaats te kunnen vinden. Niet omdat een nieuwe dosis pech roet in het eten gooit, maar omdat die nieuwe liefde helemaal niet blijkt te bestaan. De foto's die hij stuurde blijken van internet geplukt te zijn of te zijn gefotoshopt. De prins op het witte paard bleek te bestaan uit drie Nigeriaanse twintigers, die er lachend met het geld vandoor zijn. De vrouw ziet haar spaargeld nooit meer terug: ze is opgelicht.

Deze vorm van oplichting staat bekend als datingfraude. Datingfraude wordt gekenmerkt doordat een persoon zich op internet voordoet als iemand anders en zo een liefdesrelatie aangaat met het slachtoffer om deze voor grote geldbedragen 
op te lichten. ${ }^{1}$ Datingfraude is een vorm van voorschotfraude. Voorschotfraude wordt ook wel Nigeriaanse fraude genoemd, omdat deze vorm van oplichting in dat land is ontstaan. ${ }^{2}$ Bij voorschotfraude wordt het slachtoffer iets moois in het vooruitzicht gesteld, maar moet hij wel eerst even geld overmaken om daarover te beschikken. Voorbeelden hiervan zijn mailtjes waarin verheugd gemeld wordt dat de ontvanger een loterij gewonnen heeft, of dat een rijke, terminaal zieke weduwe een fortuin aan de ontvanger na wil laten. Uiteraard ziet het slachtoffer de 'administratiekosten' die hij hiervoor betaalt nooit meer terug. Voorschotfraude vond ook al plaats voordat het internet zijn intrede deed. Toen werden vanuit Nigeria brieven verstuurd met als doel de ontvanger op te lichten. Maar op het internet maken online datingsites het voor oplichters mogelijk om hun netten breder uit te werpen en om makkelijker te verdwijnen dan in het analoge tijdperk. ${ }^{3}$ Nigeriaanse fraude vindt dan ook al lang niet meer alleen vanuit Nigeria plaats: het is een mondiaal fenomeen geworden.

Datingfraude heeft de afgelopen jaren steeds meer aandacht gekregen, in krantenartikelen, maar bijvoorbeeld ook in televisieprogramma's, zoals Pauw en Opgelicht?!, waarin slachtoffers naar buiten treden met hun verhaal. ${ }^{4}$ Toch is er nog veel onbekend over datingfraude. In deze bijdrage wordt daarom ingegaan op hoe datingfraude plaatsvindt. Wie zijn de slachtoffers? En wie zijn de daders? Wat zijn de gevolgen van datingfraude en hoe kan het worden voorkomen?

\section{Hoe vindt datingfraude plaats?}

Rege beschrijft datingfraude als een proces dat uit verschillende fasen bestaat. ${ }^{5}$ De eerste fase betreft de voorbereidende fase: op één of meerdere online datingsites wordt een profiel aangemaakt met een valse identiteit, met een aansprekende tekst erbij. Oplichters kunnen zich voordoen als wie dan ook: ze kunnen makkelijk veranderen van naam, e-mailadres, foto, geslacht, ras, leeftijd en seksuele geaardheid. De oplichter doet zich bijvoorbeeld vaak voor als een Amerikaanse of Britse militair, zakenman of engineer, zodat het later voor het slachtoffer aannemelijk is dat hij voor zijn werk naar het buitenland moet reizen en het slachtoffer niet op korte termijn in het echt kan ontmoeten. De foto die de oplichter op het profiel plaatst, is meestal van internet geplukt. Vaak worden foto's van modellen gekozen, niet alleen omdat een aantrekkelijke foto tot meer reacties op de datingsite leidt, maar ook omdat er van modellen vaak veel foto's op internet

1 In deze bijdrage wordt voor de leesbaarheid bij de beschrijving van datingfraude vaak gesproken over een mannelijke internetliefde die een vrouwelijk slachtoffer oplicht, maar de (al dan niet valselijk voorgewende) geslachten komen in alle combinaties voor.

2 Een andere benaming is 419-fraude, een verwijzing naar het wetsartikel waarin in Nigeria oplichting strafbaar is gesteld.

3 A. Rege, 'What's Love Got to Do with It? Exploring Online Dating Scams and Identity Fraud', International Journal of Cyber Criminology 2009, 2, p. 494-512.

4 De programma's zijn online te bekijken op: www.npo.nl/pauw/30-08-2016/VARA_101380273/ POMS_VARA_4958849 en op https://opgelicht.avrotros.nl/uitzending/uitzending-gemist/28-01 -2014/fragment/925/.

5 Rege 2009. 
staan, waardoor de dader een ruime keuze heeft uit foto's die hij later aan zijn slachtoffer stuurt. ${ }^{6}$

De tweede fase is de contactfase. De oplichter neemt bijna altijd het initiatief voor het contact met het slachtoffer. Om aan eventuele controles door de datingsite te ontkomen probeert de oplichter gauw om het contact te verplaatsten naar e-mail, Skype of WhatsApp. ${ }^{7}$ Door in te spelen op de gevoelens van het slachtoffer probeert de oplichter snel een persoonlijke band te krijgen en een liefdesrelatie op te bouwen. Hierbij gebruikt hij informatie die hij online over het slachtoffer kan vinden om te 'spiegelen': ${ }^{8}$ als het slachtoffer weduwe is, is hij weduwnaar. Als het slachtoffer bepaalde hobby's of interesses heeft, heeft hij ze ook. De oplichter is zeer begripvol en attent en probeert zo het vertrouwen van het slachtoffer te winnen. De contacten zijn frequent en intens: het slachtoffer wordt overspoeld met aandacht. De oplichter laat het slachtoffer vrij snel weten verliefd te zijn. ${ }^{9}$ Deze opbouwfase kan maanden duren. ${ }^{10}$

De derde fase betreft de fase waarin de verzoeken om geld worden gedaan. Soms vraagt de oplichter het slachtoffer eerst om iets kleins, om diens bereidheid om te helpen te testen. ${ }^{11}$ De oplichter maakt het slachtoffer deelgenoot van tragische omstandigheden waarin hij terecht is gekomen. Voor de ziekenhuisrekeningen die betaald moeten worden, of de gestolen reisdocumenten die vervangen moeten worden, wordt een beroep op het slachtoffer gedaan. Als het slachtoffer betaald heeft, blijken tragische gebeurtenissen elkaar in rap tempo op te volgen; de oplichter vraagt steeds om meer geld. ${ }^{12}$ Soms worden derden ingeschakeld om het verhaal van de oplichter kracht bij te zetten, of om op een nieuwe manier geld te vragen. Zo kan het slachtoffer opgebeld worden door een 'arts' die uitlegt dat de geliefde gewond is geraakt bij een ongeluk en dat de ziekenhuisrekening betaald moet worden. ${ }^{13}$ Ook kan de 'dochter' opbellen om te vertellen dat haar vader zo intens gelukkig is met zijn nieuwe relatie. Zo wordt er meer emotionele druk op het slachtoffer uitgeoefend. Het slachtoffer wordt gevraagd te betalen via Western Union of MoneyGram: er is dan geen bankrekening nodig. ${ }^{14}$

De fraude houdt pas op als het slachtoffer doorheeft dat hij is opgelicht. Maar omdat liefde blind maakt, duurt het vaak lang voordat het slachtoffer inziet dat zijn nieuwe liefde een oplichter is. Soms had een slachtoffer pas door dat hij is

6 Rege 2009. Ook foto's van de Nederlandse oorlogsheld Marco Kroon zijn door datingfraudeurs gebruikt op Amerikaanse datingsites ('Leger onderzoekt fraude', Algemeen Dagblad 11 augustus 2015, p. 7).

7 Fraudehelpdesk, Datingfraude. Informatie voor melders, 2017, brochure te downloaden via www. fraudehelpdesk.nl/wp-content/uploads/2017/04/Datingfraude-brochure1.pdf.

8 Fraudehelpdesk 2017.

9 T. Buchanan \& M.T. Whitty, "The online dating romance scam: Causes and consequences of victimhood', Psychology, Crime \& Law 2014, 3, p. 261-283.

10 Rege 2009.

11 Buchanan \& Whitty 2014.

12 Rege 2009.

13 Rege 2009; M.T. Whitty \& T. Buchanan, 'The online dating romance scam: The psychological impact on victims - both financial and non-financial', Criminology \& Criminal Justice 2016, 2, p. 176-194.

14 www.fraudehelpdesk.nl/fraude-abc/hoe-herken-datingfraudeur/. 
opgelicht toen hij op Schiphol zijn Russische internetvriendin tevergeefs stond op te wachten. Zijn 30.000 euro heeft hij net als zijn vriendin nooit meer gezien. ${ }^{15}$ Voor omstanders is het moeilijk om het slachtoffer te laten inzien dat er sprake is van oplichting: het slachtoffer wil door de hechte band met de oplichter niet geloven dat het allemaal nep is. In plaats daarvan geloven slachtoffers vaak dat er toch iets oprechts in de relatie zit. Dat maakt ze vatbaar voor een tweede oplichtingsgolf, vooral als de oplichter het slachtoffer bijvoorbeeld wijs maakt dat hij haar aanvankelijk wel wilde oplichten, maar dat hij gaandeweg echt verliefd op haar is geworden. Een tweede oplichtingsgolf kan ook plaatsvinden als de oplichter, of een door hem ingeschakelde derde, zich voordoet als bijvoorbeeld een detective die ervoor kan zorgen dat het slachtoffer zijn geld terugkrijgt. ${ }^{16}$ Er is dan sprake van recovery fraud. ${ }^{17}$

\section{Omvang}

De omvang van datingfraude is niet precies bekend. De politie registreert aangiftes alleen als oplichting en heeft geen specifieke cijfers over datingfraude. De Fraudehelpdesk heeft die wel. Deze helpdesk is in 2003 opgericht onder de paraplu van Stichting Aanpak Financieel-Economische Criminaliteit in Nederland (SafeCin) en probeert fraude te voorkomen door mensen bewust te laten zijn van risico's en door actief barrières tegen oplichters op te werpen. Daarnaast richt de Fraudehelpdesk zich op de zorg voor slachtoffers door de door hen of hun naasten gemelde zaken zo goed mogelijk in kaart te brengen, hun aandacht te geven en te verwijzen naar begeleiding door specialisten. ${ }^{18}$ De Fraudehelpdesk registreerde sinds 2003 een sterkte stijging van het aantal meldingen van datingfraude. In de periode 2014-2016 is jaarlijks door of namens zo'n 130 slachtoffers bij de Fraudehelpdesk schade door datingfraude gemeld van totaal ruim 2,5 miljoen euro. Dat is ruim 19.000 euro per slachtoffer. ${ }^{19}$ Het hoogste schadebedrag van datingfraude dat bij de Fraudehelpdesk bekend is, is van een getrouwde vrouw die 150.000 euro overmaakte aan haar internetliefde, die zich voordeed als een Duitse ingenieur op een booreiland. ${ }^{20}$

Het is zeer aannemelijk dat dit slechts het topje van de ijsberg is, omdat slachtoffers uit schaamte geen aangifte of melding willen doen van het delict. Bovendien

In het televisieprogramma Opgelicht?! vertelt Danny dat hem dit overkwam (https://opgelicht. avrotros.nl/uitzending/uitzending-gemist/28-01-2014/fragment/925/).

16 Whitty \& Buchanan 2016.

17 www.fraudehelpdesk.nl/fraude-abc/recoveryfraude/.

18 Stichting Aanpak Financieel-Economische Criminaliteit in Nederland, Financieel verslag 2014, te raadplegen via www.fraudehelpdesk.nl/wp-content/uploads/2015/04/Jaarrekening-2014SafeCin.pdf.

19 Deze cijfers zijn afgeleid uit de jaarverslagen van SafeCin, waar de Fraudehelpdesk onder valt. In 2014 waren er 134 slachtoffers met een gemiddelde schade van $€$ 19.754, in 2015133 slachtoffers met een gemiddelde schade van $€ 20.461$, en in 2016128 slachtoffers met een gemiddelde schade van $€$ 17.100. De jaarverslagen zijn te raadplegen via www.fraudehelpdesk.nl/over-ons/ jaarverslagen/.

20 'Internetliefde vaker duur betaald', De Telegraaf 2 augustus 2016, p. 6. 
levert het doen van aangifte de slachtoffers weinig op: de politie kan er vaak niet veel mee omdat het slachtoffer vrijwillig geld heeft overgemaakt aan zijn internetliefde in het buitenland. Datingfraude kent dan ook een aanzienlijk dark number. De Fraudehelpdesk heeft zelf berekend dat het werkelijke aantal gevallen van datingfraude waarschijnlijk tien keer hoger ligt. ${ }^{21}$ Uit ander onderzoek blijkt dat datingfraude zo omvangrijk is dat het een aanzienlijke inkomstenbron in Nigeria is: jaarlijks komt er door deze vorm van fraude ongeveer 45 miljoen dollar het land binnen. ${ }^{22}$

\section{Slachtoffers}

Wie maakt er nu duizenden euro's over naar een persoon die hij nog nooit in het echt ontmoet heeft? Hoewel Jaap Jongbloed in een interview over zijn rol als presentator van Opgelicht?! meent dat oplichters zich veelal richten 'op de labiele leden van de samenleving', ${ }^{23}$ blijkt uit onderzoek dat slachtofferschap onder alle delen van de samenleving voorkomt. Volgens Rege is datingfraude genderneutraal: het richt zich evenveel op mannelijke als op vrouwelijke slachtoffers. ${ }^{24}$ Ook met opleidingsniveau heeft het niets te maken: onder de slachtoffers bevinden zich ook dierenartsen en oncologen. ${ }^{25}$ Volgens de Fraudehelpdesk zijn slachtoffers die de grootste bedragen verliezen wel vaak vrouwen van middelbare leeftijd, die eenzaam zijn, een christelijke achtergrond hebben en in de zorg werkzaam zijn. Naastenliefde was voor hen een belangrijke reden de oplichter te helpen. Daarnaast zijn mensen die goedgelovig en gul zijn vaker slachtoffer. ${ }^{26}$ Buchanan en Whitty onderzochten onder een (niet-representatieve) steekproef van gebruikers van een Engelse datingsite of eenzaamheid, extraversie, servicegerichtheid (anderen helpen), geloof in romantiek, sensatiegerichtheid en neuroticisme voorspellers zijn van slachtoffers van datingfraude. Uit hun onderzoek bleek dat alleen mensen die sterk geloven in romantiek een grotere kans hebben om slachtoffer te worden van datingfraude. ${ }^{27}$

Doordat slachtoffers helemaal ingepakt zijn door de oplichter, trappen ze in het samenweefsel van verdichtsels dat hij hun voorhoudt. Door de overvloed aan berichtjes krijgt het slachtoffer aandacht en het gevoel voor iemand heel belangrijk te zijn. In een televisieprogramma licht een slachtoffer toe dat ze zich gevleid voelde door alle liefdesmailtjes die ze ontving: 'Dat vindt iedere vrouw leuk om te krijgen. ${ }^{28}$ De slachtoffers doen dan graag iets voor hun nieuwe liefde terug. Slachtoffers zijn door hun omgeving ook moeilijk te overtuigen dat ze opgelicht 
worden, omdat ze 'verslaafd' zijn aan de aandacht die ze van hun internetliefde krijgen. ${ }^{29}$

Daarnaast maakt de oplichter gebruik van een verfijnd geconstrueerd web van leugens. Slachtoffers maken niet zomaar geld over: ze hebben op internet wel eerst naar informatie gezocht om de verhalen van de oplichter te verifiëren. Maar ze zagen dat die informatie vaak bleek te kloppen. Bedrijven die de oplichter in zijn berichten noemde, blijken te bestaan. Als het slachtoffer op verzoek van de oplichter inlogt op diens bankaccount, blijkt er inderdaad een paar ton op zijn (geblokkeerde) rekening te staan (althans, op de nepwebsite van de bank). ${ }^{30} \mathrm{Als}$ het slachtoffer aangeeft geen geld over te willen maken omdat hij het niet helemaal vertrouwt, kan hij het nummer bellen van de nicht van de oplichter, die in Nederland woont. Deze 'nicht' bevestigt hoe betrouwbaar haar aardige neef is. ${ }^{31}$ De daders gaan dus zo geraffineerd te werk dat niet alleen hele naïeve mensen in hun val lopen.

\section{Daders}

\section{Profiel van Nigeriaanse datingfraudeurs}

Wie zijn die daders van datingfraude dan? Volgens de Nigeriaanse sociologen Aransiola en Asindemade zijn de daders in Nigeria makkelijk te herkennen aan hun levensstijl: '[They] usually brag, sag, do things loudly, drive flashy cars, and change cars frequently. They turn their music loud and wear expensive and latest clothes and jewelry. They also have a special way of dressing and relate, they spend lavishly, love material things, and go to clubs. ${ }^{32}$ Verder gaan ze vaak op stap in kleine groepjes en maken ze onderling gebruik van codetaal om bijvoorbeeld aan te geven dat het slachtoffer betaald heeft. Oplichters streven ernaar om wekelijks in ieder geval twee of drie keer geld binnen te krijgen van een slachtoffer. In goede maanden verdienen ze 30.000 dollar. $^{33}$

Toch gaat er veel meer schuil achter de datingfraudeurs. De fraudeurs zijn slimme jongens: vaak studeren zij aan de universiteit. ${ }^{34}$ Het cybercafé van waaruit gewerkt wordt, doet door de stilte en concentratie waarmee gewerkt wordt denken aan een universiteitsbibliotheek. ${ }^{35}$ De oplichters hebben meerdere 'zaken' tegelijkertijd lopen. Rege beschrijft in zijn profielschets van datingfraudeurs dat fraudeurs verder geduldig en volhardend zijn. ${ }^{36}$ In de maanden die het duurt om

'Online verliefd en dan kaalgeplukt', Trouw 20 april 2015, p. 7.

'Datingfraude neemt explosief toe', de Volkskrant 4 augustus 2016, p. 13.

Dit is het slachtoffer overkomen dat in Opgelicht?! haar verhaal doet (zie https://opgelicht. avrotros.nl/uitzending/uitzending-gemist/28-01-2014/fragment/925/).

2 J.O. Aransiola \& S.O. Asindemade, 'Understanding Cybercrime Perpetrators and the Strategies They Employ in Nigeria', Cyberpsychology, behavior, and social networking 2011, 12, p. 760.

Rege 2009.

34 Dixon 2005; O. Tade, 'Meet the "Yahoo boys" - Nigeria's undergraduate conmen', The Conversation 26 juli 2016, te raadplegen via http://theconversation.com/meet-the-yahoo-boys-nigeriasundergraduate-conmen-60757.

Dixon 2005.

Rege 2009. 
een vertrouwensband en liefdesrelatie met het slachtoffer op te bouwen zijn de daders ook rationeel en georganiseerd. De oplichters zijn geen amateuristische solisten: zij maken deel uit van een hele 'oplichtingscultuur'. In de groep oplichters worden middelen en technieken gedeeld. Nieuwe leden worden opgeleid om hen de kneepjes van het vak bij te brengen. Technische kennis van computers is nauwelijks nodig: de enige expertise die oplichters moeten hebben is gelegen in sociale vaardigheden. De oplichters draaien shifts van zes uur en hebben de taken goed verdeeld. Het ene groepslid verzamelt informatie over het slachtoffer, het andere maakt de planning van de tragische gebeurtenissen die de aanleiding vormen om geld van het slachtoffer te vragen. Als het profiel eenmaal aangemaakt is en het noodlotscenario is ontwikkeld, kunnen ze gelijktijdig en herhaaldelijk verschillende slachtoffers oplichten. ${ }^{37}$

De hoge organisatiegraad blijkt ook uit de inzet van derden. Een vrouw wordt ingehuurd en voor de webcam gezet, terwijl de oplichter het toetsenbord bedient om met het slachtoffer te chatten. Of zij wordt gevraagd het slachtoffer te bellen en te doen alsof ze bijvoorbeeld de dochter van de nieuwe internetliefde is. Behalve de inzet van derden die direct contact hebben met het slachtoffer, worden er ook derden achter de schermen ingezet. Soms wordt er een psycholoog ingehuurd om het slachtoffer verder psychisch klem te zetten, ${ }^{38}$ of worden bankmedewerkers bij de oplichting betrokken om het geld van de money transfer onder een valse identiteit op te kunnen halen. ${ }^{39}$ Het netwerk omvat ook kompanen in het buitenland, zodat een zaak ondersteund kan worden door lokale cellen. Dat kan een oplichter zijn die zich voordoet als een collega van de internetliefde die een koffer met (nep)geld af komt geven bij het slachtoffer, waar het slachtoffer dan nog wel een paar duizend euro aan kosten voor moet betalen. Ook kunnen het mensen zijn die als katvanger hun rekening en identiteit beschikbaar stellen om de fraude te faciliteren. Of, zoals te zien is in de aflevering van Opgelicht?!, de Nederlandse vrouw die zich voordeed als de nicht van de oplichter. ${ }^{40}$ Door tegen het slachtoffer te zeggen: 'Het is echt een nette man. Je hebt het geld zo terug van hem. Echt waar', gaf zij het slachtoffer het laatste zetje in de rug dat nodig was om het geld over te maken.

\section{Motieven}

De motieven voor de fraudeurs zijn duidelijk. Zij zien om zich heen dat met oplichting veel geld verdiend kan worden. Voor studenten aan de universiteit is geld verdienen door oplichting vaak een beter alternatief dan wachten op de werkloosheid die hen na de studie staat te wachten. ${ }^{41}$ Morele bezwaren worden daarbij niet gezien of weggewuifd: slachtoffers worden niet als slachtoffer gezien. Blanken zijn immers toch altijd rijk en hebben altijd geld en bovendien zijn ze zelf

40 https://opgelicht.avrotros.nl/uitzending/uitzending-gemist/28-01-2014/fragment/925/.

41 Tade 2016. 
zo stom om erin te trappen. ${ }^{42}$ Die visie werd ook geuit in een populair Nigeriaans lied, waarin de Nigeriaanse fraude wordt verheerlijkt. Slachtoffers worden in dat lied als sukkels weggezet: 'You be the mugu [victim], I be the master... I go chop your dollar, I go take your money and disappear. 419 is just a game, you are the loser I am the winner.' 43

\section{Gevolgen voor slachtoffers}

Voor de oplichters is datingfraude dus een groot spel. Voor de slachtoffers is dat anders. De financiële gevolgen door de oplichting kunnen groot zijn. Slachtoffers hebben soms al hun spaargeld of het geld voor de studie van de kinderen overgemaakt, of hebben waardevolle spullen verkocht om geld over te kunnen maken, en soms zijn zij leningen aangegaan om geld over te kunnen maken. Het betrof immers maar een tijdelijke lening aan de internetliefde; het geld zou worden terugbetaald. De bedragen die slachtoffers kwijt zijn geraakt, lopen uiteen van enkele honderden tot tienduizenden euro's, of nog meer. Een 75-jarige Nederlandse vrouw is bijvoorbeeld voor zo'n twee ton opgelicht door een 31-jarige Nigeriaan. ${ }^{44}$

Maar de gevolgen voor slachtoffers beperken zich niet tot het financiële terrein: datingfraude zorgt voor een double hit. ${ }^{45}$ Slachtoffers zijn niet alleen hun geld kwijt, maar ook hun relatie met de 'partner' die hun zo veel aandacht gaf. Voor veel slachtoffers is de emotionele schade nog erger dan de financiële. ${ }^{46}$ Hun vertrouwen is vreselijk beschaamd. De schade op emotioneel vlak omvat bovendien niet alleen het verlies van een waardevolle liefdesrelatie. Hun gevoel van eigenwaarde, vertrouwen en autonomie is ook beschadigd. ${ }^{47}$ Bovendien komen relaties met anderen onder druk te staan. Op begrip vanuit de sociale omgeving hoeft het slachtoffer meestal niet te rekenen: 'Hoe kun je nu zo stom zijn' is de standaardreactie die het slachtoffer krijgt. ${ }^{48}$ Als dan ook nog blijkt dat geld is overgemaakt uit de gemeenschap van goederen, of uit het studiepotje van de kinderen, bescha-

Hierin zijn de door Sykes en Matza beschreven neutralisatietechnieken van 'ontkenning van de schade' en 'ontkenning van het slachtoffer' te herkennen: G.M. Sykes \& D. Matza, 'Techniques of neutralization: A theory of delinquency', American Sociological Review 1953, 6, p. 664-670. Osuofia, I go chop your dollar, te bekijken op www.youtube.com/watch?v=cG57mPMiJvw. www.telegraaf.nl/binnenland/23049383/_Nigeriaan_licht_Nederlandse_op_html. M.T. Whitty \& T. Buchanan, 'The online romance scam: A serious cybercrime', Cyberpsychology, Behavior, and Social Networking 2012, 3, p. 181-183; https://www2.le.ac.uk/departments/media/ people/monica-whitty/Whitty_romance_scam_report.pdf.

46 M.T. Whitty \& T. Buchanan, 'The online dating romance scam: The psychological impact on victims - both financial and non-financial', Criminology \& Criminal Justice 2015, 2, p. 176-194.

47 S. Berg, 'Identity Theft Causes, Correlates, and Factors: A Content Analysis', in: F. Schmalleger \& M. Pittaro (red.), Crimes of the Internet, New Jersey: Pearson Prentice Hall, p. 225-250.

48 Er zijn ook heftigere reacties van naasten bekend. Toen de echtgenoot van een 62 -jarige vrouw uit Los Angeles erachter kwam dat zij 264.000 pond had overgemaakt om de winst van een loterij overgemaakt te krijgen, schoot hij eerst haar dood en daarna zichzelf (www.dailymail.co.uk/news/ article-2242985/Jailed-London-based-Nigerian-fraudsters-ran-2-7million-lotto-scam-led-murdersuicide.html). 
digt dat de relatie tussen het slachtoffer en diens naasten nog meer. Dit is zwaar voor slachtoffers: zij zijn letterlijk alles kwijt.

Slachtoffers ervaren door de datingfraude veel negatieve emoties, zoals boosheid, wrok, angst, nervositeit en depressie. ${ }^{49}$ Volgens de Fraudehelpdesk overweegt $60 \%$ van de slachtoffers van datingfraude zelfmoord. Bij de Fraudehelpdesk zijn verschillende gevallen bekend van slachtoffers die daadwerkelijk een einde aan hun leven maakten. ${ }^{50}$ En volgens een fraude-expert neemt het aantal zelfmoorden als gevolg van datingfraude steeds verder toe. ${ }^{51}$

\section{Conclusie}

De online datingmarkt, die zo veel mensen in contact brengt met potentiële liefdespartners, heeft een keerzijde. Datingfraude veroorzaakt enorme schade. Op financieel gebied gaan slachtoffers vaak voor duizenden euro's het schip in, maar de emotionele schade bij slachtoffers en hun naasten is ook groot. Het is daarom belangrijk dat datingfraude wordt aangepakt.

Maar dat er in Nederland pas één keer een veroordeling heeft plaatsgevonden in verband met datingfraude, geeft aan dat datingfraude nu nauwelijks wordt aangepakt. ${ }^{52}$ Fraudeurs hebben vrij spel. De aanpak van datingfraude is ook erg moeilijk: 'The few and weak countermeasures, the ease of creating dating profiles, an increasing supply of victims, the reluctance of reporting victimization, their social skill prowess, their rationales and justifications, and their untouchable and anonymous status, grants these romance scammers a sanctuary in cyberspace. ${ }^{.53}$

De datingfraudeurs hebben maar een hele kleine kans om gepakt te worden en een grote kans om geld binnen te halen. De opsporing van de oplichters gebeurt maar zelden proactief. Vaak is er alleen een report abuse-knop op de website. ${ }^{54}$ De gebruikers van de datingsite zijn daarmee degenen die aan zet zijn om de fraudeur te stoppen. Bij de politie heeft de opsporing van datingfraudeurs weinig prioriteit. ${ }^{55}$ Volgens een woordvoerder van de Fraudehelpdesk ziet de politie het vaak niet als strafbaar feit, met het argument dat het slachtoffer vrijwillig geld heeft overgemaakt. ${ }^{56}$ Een eerste stap in de aanpak van datingfraude kan daarom zijn het creëren van meer bewustwording bij politie en justitie van de strafbaarheid van deze vorm van fraude. Als de politie het slachtoffer meer gaat zien als

49 Berg 2009.

50 'Ten einde raad door ID-fraude; Centrale aanpak van bedrog ontbreekt', De Telegraaf 23 januari 2014, p. 7; 'Slachtoffers kwetsbaar en eenzaam', De Telegraaf 1 augustus 2016, p. 3.

51 'Datingfraude neemt explosief toe', de Volkskrant 4 augustus 2016, p. 13.

52 De verdachte is veroordeeld tot een werkstraf van 50 uur voor medeplichtigheid aan poging tot oplichting door zijn bankrekeningnummer - vanwege verliefdheid en eigenbelang - ter beschikking te stellen, waarna hij de bedragen die daarop door het slachtoffer gestort zijn, heeft overgemaakt naar een buitenlandse bankrekening of heeft doorgestort via Western Union (ECLI:NL:RBMNE:2016:1433).

53 Rege 2009, p. 508.

54 Rege 2009.

55 'In een val van drie ton gelopen', NRC Handelsblad 24 december 2015.

56 'Slachtoffers datingfraude kunnen nergens terecht', Trouw 20 april 2015, p. 3. 
een slachtoffer van een criminele organisatie die onschuldige mensen op geraffineerde wijze geld afhandig maakt, gaan slachtoffers wellicht ook eerder aangifte doen. Als datingfraude meer aandacht krijgt bij politie en justitie, biedt dat ook meer mogelijkheden voor structurele internationale samenwerking bij de aanpak van de grensoverschrijdende fraude.

Vooralsnog lijkt de beste manier om datingfraude de kop in te drukken te liggen in voorlichting aan internetgebruikers. De Fraudehelpdesk informeert burgers over de signalen van datingfraude en geeft tips om slachtofferschap van datingfraude te voorkomen. Sommige tips zijn misschien wel erg voor de hand liggend ('maak nooit geld over'), maar andere informatie kan tot meer bewustwording leiden dat niet iedereen op internet is wie hij zegt te zijn. Zo geeft de Fraudehelpdesk onder andere aan dat wereldwijd één op de tien Facebookprofielen nep is. ${ }^{57}$ Toch is het maar de vraag of datingfraude hierdoor kan worden voorkomen. Slachtoffers weten heel goed dat er oplichters op internet rondwaren, zij kunnen zich alleen niet voorstellen dat hun attente internetliefde tot die groep behoort. Liefde maakt nu eenmaal blind. En zolang slachtoffers verblind zijn door alle positieve aandacht die ze van hun internetliefde krijgen, kunnen datingfraudeurs hun slag slaan. Rege waarschuwt dan ook: 'Online romance scams are here to stay. The booming online dating industry with its ever increasing membership continues to offer scammers with a ready pool of suckers that are ideal for exploitation.' Zolang er een mogelijkheid is, is er een dief. Het is daarom ook belangrijk dat datingsites meer doen om profielen van fraudeurs te weren. Te denken valt aan een proactief systeem dat profielen blokkeert, waarmee gelijk na aanmelding honderden berichten worden verstuurd, en aan uitwisseling van gegevens van fraudeurs tussen datingsites. 